\title{
The Impact of Veteran Students on the Academic Performance of Non-Veteran Students
}

\section{Dr. Patrick Bass, The Citadel}

Patrick Bass is an assistant professor in the Department of Mechanical Engineering at The Citadel, in Charleston, SC. He received his B.S. degree in aerospace engineering from Embry-Riddle Aeronautical University, Daytona Beach, FL, in 2005, his M.E. degree in space operations from the University of Colorado, Colorado Springs, CO, in 2009, and his Ph.D. in materials engineering from Auburn University, Auburn, AL, in 2016. His main areas of research interest are electroactive polymers and space mechanics.

\section{Dr. Nathan John Washuta P.E., The Citadel}

Dr. Nathan Washuta is an Assistant Professor in the Department of Mechanical Engineering at The Citadel in Charleston, SC. He received both his B.S. and Ph.D. in Mechanical Engineering from The University of Maryland - College Park. His primary research interests include Hydrodynamics, Turbulence, and Experimental Methods.

\section{Mr. Donald L Price, The Citadel}

I am a US Army veteran and now soon to be a Mechanical Engineer from the Citadel. I grew up in St. Augustine, Florida, and joined the Army in 2010 as a 25S- Satellite Communication Systems OperatorMaintainer. During that time, I was trained and received certifications in IT-related work and Fiber Optic communications. Additionally, I am starting grad school at Colorado School of Mines for Advanced Energy Systems in the Fall of 2020. 


\title{
Assessing Veteran Student Impact on Academic Performance of Non-Veteran Students
}

\begin{abstract}
This work-in-progress paper discusses the positive, quantitative impact of veteran students on the academic performance of non-veteran mechanical engineering students when veterans are in their classes. This paper will highlight the successful results of a yearlong study of junior-level students after the completion of a two-semester course sequence in control systems. These results show the influence veterans have and how their military experience can benefit non-military students in their pursuit of an engineering degree.
\end{abstract}

Veteran students are highly regarded for their professionalism, maturity, and for setting the example both inside the classroom and out. In general, it is easy to see that a veteran presence in the classroom positively effects the performance of the other students in the course. This report, however, focuses on quantifying the effect of veteran students on the academic performance of their non-veteran counterparts.

This report will show how non-veteran performance was influenced as it relates to eight veteran students distributed across three sections of a first-semester, control-systems course versus their effect when all eight veterans were in a single section of the follow-on, second-semester, controlsystems course. An analysis on the results of three exams and the final exam for both courses and the results show increased exam performance from one semester to the next relative to veteran student presence in a particular course section.

The results tracked individual performance of students as they transitioned to either a veteran-rich or a veteran-poor section from fall- to spring-semester courses. The study also investigated the performance of veteran students and their academic impact on the other veterans, themselves.

\section{Keywords}

Veterans, mechanical engineering, influential

\section{Introduction}

Veteran students are highly regarded for their professionalism, leadership, maturity, and for setting the example both inside the classroom and out. They bring a wealth of experience and act as role models to non-veteran students. [1] Anecdotally, it is easy to see that veteran presence in the classroom positively effects the performance of the other students in the course, given their inherent team-oriented mentality. This work-in-progress study focuses on an attempting to quantify this positive effect of veteran students on the academic performance of their non-veteran counterparts. Initial results revealed that veteran students do have a positive, quantitative impact on the grades of the non-veteran students.

The integration of veteran students into the day-program of mechanical engineering at The Citadel offered an interesting opportunity to study their effect on non-veteran students. Courses are split 
into day and night programs at The Citadel, where in the day program, all non-veteran students live in a military-style environment, whereas the evening program has a more traditional student base. All day students are in uniform and are expected to adhere to the military principles therein and are called cadets. In 2010, it was announced that veterans could attend classes with cadets. [2] Veteran students did not need to wear a uniform and would attend classes with their cadet counterparts and in this way, they could share their experiences with the students. [2] Their nonwearing of uniforms make them immediately stand out in class and an easy target for the nonveterans to gravitate to. Additionally, this made for a unique environment to evaluate veteran impact on the non-veteran students.

Veterans are experienced learners [3] and as such they have been taught through their military experience how to learn and be proficient on a new topic or process. In the military environment, not knowing how a piece of equipment works can, unfortunately, have life or death consequences. They bring this dogged determination to the classroom and typically pick up new topics faster than their non-veteran counterparts. Additionally, veteran students adapt well to new situations, are empathetic, and have developed exceptional time-management skills. [4] This compliment of skills enables them to be successful in the classroom. They also impart these characteristics on their nonveteran counterparts. The result of their mentoring leads to a more dynamic learning environment and one where non-veteran students can look to the veterans for support in helping them to understand the curriculum.

It has been found that veteran students that do pursue higher education often perform better than their non-veteran peers. [5] A study was conducted concerning the comparison of graduation GPAs for veteran and non-veteran students and it was found that the resulting GPAs were 3.34 and 2.94, respectively. [6] This disparity shows the academic horsepower that veterans bring to the classroom as well as their potential positive influence on the non-veteran students.

Veterans are excellent mentors and they routinely set the example both in and out of class. In the ME department, there is a student breakroom and routinely after classes, veterans can regularly be seen tutoring non-veteran students. Additionally, to qualify their impact on the non-veteran students, below are comments about the veteran presence in the classroom by one of the mechanical engineering faculty members and one of the veteran students studied in this report.

Faculty Member

"Having Veterans in class is a benefit to the cadets as they are able to bring real-world experiences into the classroom. The students are getting real world experience from more than the professor in class. I have witnessed many cases where the Veterans are helping the cadets solve homework problems and answering questions about projects. In addition to helping them with work, the Veterans bring a professionalism to the classroom that the cadets observe and in some cases mimic. There are more than educational benefits to having the Veterans in the classroom. Additionally, the Veterans are not only helping cadets in which they have class in, they are also helping cadets in other class sections. “

Veteran Student

"For some of the non-veteran students I do feel as if we make an impact on them. We have different backgrounds that we can pull from when doing schoolwork. Those experiences 
allow us to tell and show how different aspects of our schooling are important and are used in the real world. I have noticed that the ones that are open to outside experience do listen and try to apply what we do/say into their work. Some will even ask questions and try to learn more directly as well. An example is in control systems, when we were going over frequency and time domains. My communications background allowed me to explain that information in a different way to a couple of the other students and show how that education is applied in industry. From our work ethics, to our different knowledge bases I do think we make a positive impact on the performance of the other students.”

\section{Methods}

To conclude whether veteran students have a positive influence on the grades of non-veteran students, student averages and test scores were analyzed across a two-semester long controlsystems course. This class in control systems was part of the undergraduate mechanical engineering program curriculum with the first course offered in the fall semester and the followon course offered immediately afterwards in the spring semester. The names for the courses are MECH 350 and MECH 351 for the fall and spring, respectively Three sections were offered for the course in the fall and spring semesters. One instructor taught the three fall-semester sections and the same instructor taught two of the spring-semester offerings. This analysis will cover the results of the courses that this sole professor taught to minimize the influence of differences in teaching styles and grading considerations utilized by the second instructor in the spring semester. Data to be analyzed for an individual student include: course average, letter grade, and test scores for three in-class exams, and final-exam grades for both courses. Table $\mathbf{1}$ shows details on the numbers of students in each section with the corresponding contingent of veteran students. Individual student flow from sections 01-03 in MECH 350 to sections 02-03 in MECH 351 will be tracked and analyzed. Section 01 of MECH 351 was taught by a separate instructor and will not be included in this analysis, as indicated. All the veteran students registered for Section 03 of MECH 351. It is this concentration of veteran students that has provided the opportunity to analyze the direct impact of veteran students on non-veteran student academics. It can also be seen that the spread of students across the three sections evened out in the spring semester. Additionally, inspection of the section averages between the two semesters showed an overall increase in averages for the sections. Lastly, Section 03 averages were roughly $4 \%$ higher than the other two sections for both MECH 350 and MECH 351. The factors influencing this disparity are currently being studied and will be delivered as work on this topic continues in future research.

Table 1: Average Grades and Student Numbers for MECH 350 and MECH 351

\begin{tabular}{cccccccc}
\hline \hline $\begin{array}{c}\text { MECH } \\
\text { 350 }\end{array}$ & $\begin{array}{c}\text { Section } \\
\text { Avg. }\end{array}$ & $\begin{array}{c}\text { Total } \\
\text { Students }\end{array}$ & $\begin{array}{c}\text { Veteran } \\
\text { Students }\end{array}$ & $\begin{array}{c}\text { MECH } \\
\mathbf{3 5 1}\end{array}$ & $\begin{array}{c}\text { Section } \\
\text { Avg }\end{array}$ & $\begin{array}{c}\text { Total } \\
\text { Students }\end{array}$ & $\begin{array}{c}\text { Veteran } \\
\text { Students }\end{array}$ \\
\hline Section 01 & 81.8 & 27 & 2 & Section 01 & 84.1 & 21 & 0 \\
Section 02 & 80.1 & 27 & 3 & Section 02 & 83.9 & 22 & 0 \\
Section 03 & 84.1 & 14 & 4 & Section 03 & 88.9 & 25 & 9 \\
\hline \hline
\end{tabular}

\section{Data and Analysis}


In analyzing the impact of student academic performance by veteran presence, individual student performance was tracked from fall to spring semesters in MECH 350 and MECH 351, respectively. Both courses employed three in-class exams delivered throughout the semester and a final exam. These scores, along with the student's overall performance in the course were used to measure veteran impressions. A comparison of exam averages for the sections can be seen in Figure 1.a. It is clear that the exam average of the $\mathrm{MECH}$ 351-03 section outpaces the other five sections considered here. This section contained all the veteran students. Additionally, final letter grades for these courses are shown in Figure 1.b and again, this section fared better than the other sections. These results show positive correlation with veteran presence, but further dissection of the data is required to determine the veteran role in student performance. As work continues on this topic, with building a larger sample size, a broader statistical analysis will be conducted.
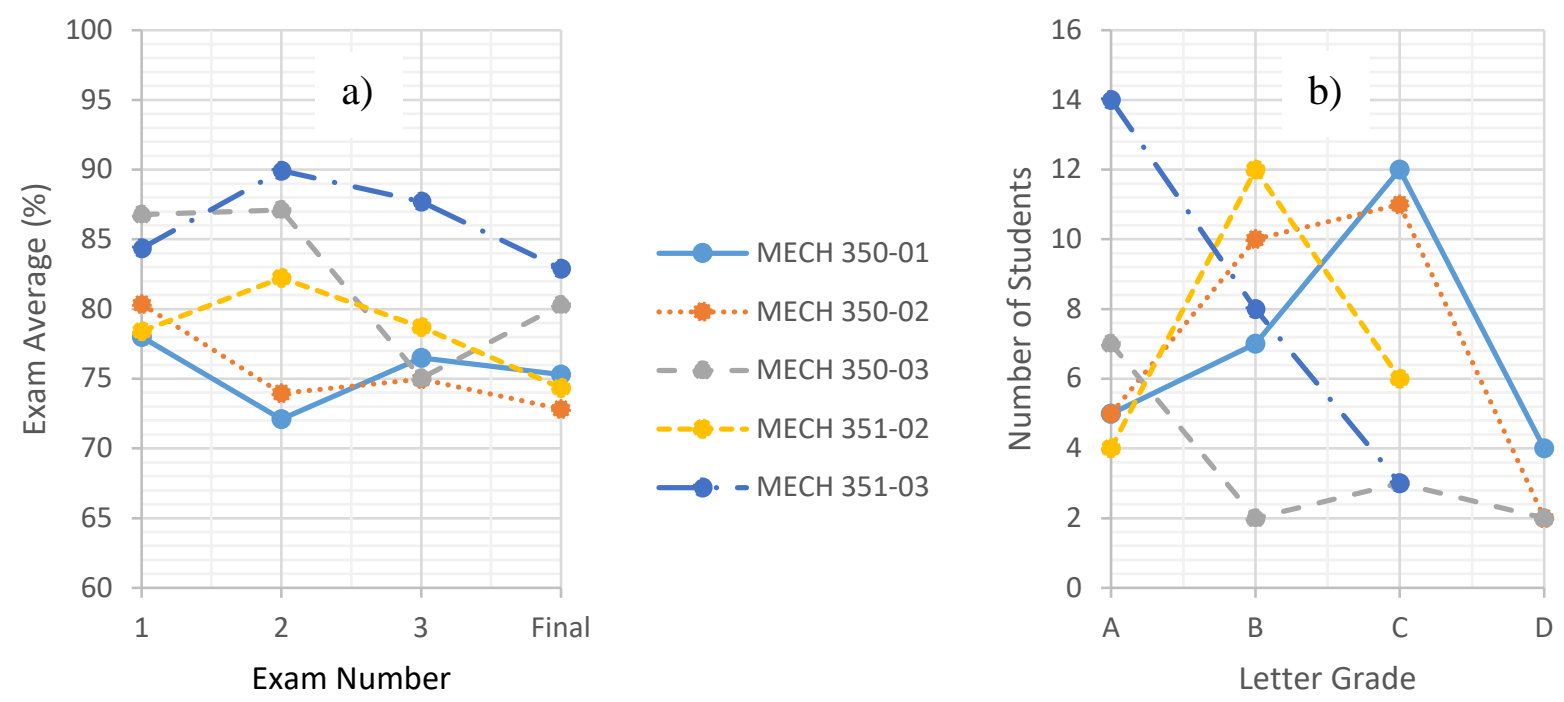

Figure 1: Tracking student performance with regards to a) individual exam results and b) overall course grade

Table 2 breaks the section data down to performance between veteran and non-veteran students. The table details grade performance for non-veteran and veteran students as they moved between sections from fall to spring. As mentioned previously, analyzing the results from Section 1 of MECH 351 was eliminated due to a different instructor teaching that section.

Table 2: Fall-to-Spring Academic Performance for Veteran and Non-Veteran Students

\begin{tabular}{ccccccccc}
\hline \hline $\begin{array}{c}\text { Student } \\
\text { Section } \\
\text { Shift }\end{array}$ & $\begin{array}{c}\text { Num. of } \\
\text { Students }\end{array}$ & $\begin{array}{c}\text { Letter } \\
\text { Grade } \\
\text { Avg. }\end{array}$ & $\begin{array}{c}\text { Letter } \\
\text { Grade } \\
\text { Increase }\end{array}$ & $\begin{array}{c}\text { Overall } \\
\text { Avg. } \boldsymbol{\Delta}\end{array}$ & $\begin{array}{c}\text { Exam } \\
\mathbf{1} \\
\text { Avg. } \boldsymbol{\Delta}\end{array}$ & $\begin{array}{c}\text { Exam } \\
\mathbf{2} \\
\text { Avg. } \boldsymbol{\Delta}\end{array}$ & $\begin{array}{c}\text { Exam } \\
\mathbf{3} \\
\text { Avg. } \boldsymbol{\Delta}\end{array}$ & $\begin{array}{c}\text { Final } \\
\text { Avg. } \boldsymbol{\Delta}\end{array}$ \\
\hline $\begin{array}{c}\text { Non-Vet } \\
01 \text { to 02 }\end{array}$ & 6 & 2.67 & 0.17 & 3.05 & 2.33 & 7.83 & 4.53 & 3.92 \\
$\begin{array}{c}\text { Non-Vet } \\
\text { 02 to 02 }\end{array}$ & 12 & 2.83 & $0.42^{*}$ & 4.05 & -1.08 & 6.17 & 9.67 & 0.21 \\
$\begin{array}{l}\text { Non-Vet } \\
\text { 03 to 02 }\end{array}$ & 4 & 2.88 & $0.25 \dagger$ & 3.88 & -5.50 & -1.88 & 21.1 & -3.25 \\
\hline
\end{tabular}




\begin{tabular}{lcccccccc}
\hline $\begin{array}{l}\text { Non-Vet } \\
01 \text { to 03 }\end{array}$ & 5 & 3.4 & 0.00 & -2.41 & -7.40 & 7.60 & -2.00 & -2.10 \\
$\begin{array}{l}\text { Non-Vet } \\
02 \text { to 03 }\end{array}$ & 9 & 2.78 & 0.67 & 5.19 & 1.33 & 15 & 7.72 & 3.28 \\
$\begin{array}{l}\text { Non-Vet } \\
03 \text { to 03 }\end{array}$ & 2 & 4.00 & 0.00 & -0.22 & 2.50 & 0.00 & -3.90 & 1.5 \\
\hline $\begin{array}{l}\text { Veteran } \\
01 \text { to 03 }\end{array}$ & 2 & 4.00 & 0.00 & -2.67 & 3.50 & 1.00 & -10.30 & 4.50 \\
$\begin{array}{l}\text { Veteran } \\
02 \text { to 03 }\end{array}$ & 3 & 2.83 & 0.33 & 7.18 & 7.33 & 13.7 & 15.5 & -1.67 \\
Veteran & 4 & 4.00 & 0.00 & -1.03 & -8.25 & 2.25 & 2.35 & -1.00 \\
03 to 03 & & & & & & & & \\
\hline \hline
\end{tabular}

*6 grade increases with 1 decrease, $\nmid 2$ grade increases with 1 decrease

There are many takeaways from Table 2 regarding the impact of having veteran students in the classroom. First, it is important to understand what each column represents; column 1 details how non-veteran and veteran students moved between sections from MECH 350 in the fall and MECH 351 in the spring; column 2 is the number of students represented in each category; column 3 is the average of the students' average letter grade between semesters; column 4 indicates the average increase in letter grade, with a score of 1 indicating an increase in one letter grade; column 5 represents the average of the change in student numeric grade; columns 6-9 similarly show the average of the change in test scores for students for exams 1-3 and the final.

Inspecting column 3 shows that overall, students in Section 02 averaged a high $\mathrm{C}$ across the two courses, while Section 03 averaged a high B for the same transition. For the subset of students coming in from Section 02, 2/3 of the non-veteran and 1/3 of the veteran students raised their grade by at least a letter grade where the students coming to Section 03 from Section 01 or 03 maintained their grade at either an A or a B with 12 of those grades being As.

Further inspection of the non-veterans and veterans coming from Section 02 to Section 03 and their resulting exam scores further shows how the movement between sections positively impacted their grades. Almost universally, for exams 1 through 3 there was an increasing trend in exam average changes from how these students performed in $\mathrm{MECH} 350$ to $\mathrm{MECH} 351$. The performance of the students staying in or moving to Section 02 lacked an overall trend. These results indicate an outside influence on the scores which may be attributed to the veterans being in the classroom. For the exam grades of veterans coming from Section 01 or staying in Section 03, the results are more up and down. Some context should be given to these results. For instance, the -10.30 in the Exam 3 column for veterans coming from Section 01 to Section 03 can be attributed to one of the students scoring a curved score of 112\% for exam 3 in MECH 350, but only a 94\% on that exam in MECH 351. There is a drop in performance, but it is from a very high A to a mid A. This outcome can be extended to the other exam scores for veterans coming from Section 01 or staying in Section 03.

Regarding column 4 in Table 2 there is evidence of the impact of veteran presence in the classroom when inspecting the non-veteran grades for MECH 351, Section 02. In this section, as a class, there were 9 increases in letter grades from the fall to the spring, with 2 decreases in letter grade. The 
decreases occurred with non-veteran students remaining in Section 02 and with non-veteran students moving from Section 03 to Section 02. Comparing Table 1 with Table 2, MECH 350, Section 03, had the largest contingent of veterans with 4 and the student in that section who moved to Section 02 in the spring had earned an A in MECH 350, but a B in MECH 351. For Section 03, there were 6 increases in letter grade with zero decreases in letter grade. In this section, there were 14 As, where 7/9 veterans had As, compared to Section 02 having 4 total As. Non-veteran students going from Section 01 to Section 03 maintained an A or a B, then two thirds of the non-veteran students migrating from Section 02 to Section 03 increased their letter grade. Concerning the veterans, of the two that did not have As in both semesters, one of them increased a letter grade with the other maintaining their $\mathrm{C}$. The veteran that maintained their $\mathrm{C}$, increased their average by $6.73 \%$, which is almost $3 \%$ higher than the average increase in grade across the semesters.

Finally, there is evidence of veterans impacting the scores of other veterans. As mentioned previously, 7/9 of the veteran students maintained an A from MECH 350 through MECH 351. For the non- $\mathrm{A}$ veterans, one increased their grade from a $\mathrm{C}$ to a $\mathrm{B}(11.5 \%$ increase in average) while the other maintained their $\mathrm{C}$ across semesters but increased their grade percentage by $6.73 \%$. Throughout the semester, the nine veterans sat next to each other in the classroom. This unity and bond between their group manifested itself as daily study groups in the student breakroom. They were dedicated to each other and the success of the group. As the semester progressed, non-veteran students joined their study group resulting in elevated performance of all the students, whether or not they were in Section 03.

\section{Conclusion}

Veterans have become a critical cornerstone to the success of The Citadel's undergraduate mechanical engineering program. They are an invaluable resource in and out of the classroom. This work-in-progress study investigated performance across a two-semester long control systems course. In the first semester, the 9 veteran students were spread across three sections of the course while in the second semester, they all registered for the same section. This concentration of veteran students in one section made it possible to show that not only do veterans anecdotally provide mentorship and guidance to the non-veteran students, but that the presence they bring in the classroom has a direct and quantitative influence on the academic performance of non-veteran students. The majority of the veterans earned an A in both MECH 350 and its companion course, MECH 351 and their strong academic aptitude increased the average grade of non-veteran students at a rate of $5.19 \%$, which was $1.54 \%$ higher than the increases in non-veteran student grades in the MECH 351 section that contained no veteran students. This initial conclusion drives the point that veterans are an asset in the classroom and that leveraging their professionalism, leadership skills, and adaptability can have a positive influence on non-veteran student academics. Future work will follow additional veterans to increase the study's sample size and to enhance the ability to perform a statistical analysis on the results. Additionally, the authors are looking to expand the research to include findings from other institutions to study the broader impacts of veteran presence in the classroom.

\section{References}


[1] M. Kirchner, L. Coryell and S. Biniecki, "Promising practices for engaging student veterans," Quality Approaches in Higher Education, vol. 5, no. 1, pp. 12-18, 2014.

[2] The Citadel, "Veterans day program reactivated beginning spring 2010," The Citadel Newsroom, 16 November 2009.

[3] J. Dougherty, "The Impact Of Military Experience On The Higher Education Experiences Of Veterans," Illinois State University, 2015.

[4] P. Granger, "Student veteran success: A grounded theory study," St. John Fisher College, 2016.

[5] C. Hill, M. Kurzweil, E. Pisacreta and E. Schwartz, "Enrolling more veterans at highgraduation-rate colleges and universities," Ithaka S+R, 2019.

[6] Institute for Veterans and Military Families and Student Veterans of America, "Student Veterans: A Valuable Asset to Higher Education," Syracuse University, 2017. 